\title{
Recommended Figures of Merit for Green Monopropellants
}

\author{
William M. Marshall ${ }^{1}$ and Matthew C. Deans ${ }^{2}$ \\ National Aeronautics and Space Administration Glenn Research Center, Cleveland, Ohio 44135
}

\begin{abstract}
Hydrazine propellant has historically been used as a rocket thruster monopropellant since the mid-1960s. Mission managers are well aware of its characteristics and performance. However, it is a known toxic chemical and a wide effort is underway to reduce and/or eliminate its use worldwide. Several new propellant combinations have been developed in the last few years which tout or promise to provide same or better performance as hydrazine while being "non-toxic" or "green". Yet, there is no consistent definition for what constitutes "non-toxic" or "green", and thus no good figure of merit for which to compare. This paper seeks to review the three major categories of figures of merit, and discusses how they might be used to assess the viability of a propellant.
\end{abstract}

\section{Nomenclature}

\begin{tabular}{|c|c|c|}
\hline APU & $=$ & Auxiliary Power Unit \\
\hline DACS & $=$ & Divert and Attitude Control System \\
\hline DOT & $=$ & Department of Transportation \\
\hline ECAPS & $=$ & Ecological Advanced Propulsion Systems \\
\hline EPA & $=$ & Environmental Protection Agency \\
\hline E. U. & $=$ & European Union \\
\hline GHS & $=$ & Globally Harmonized System \\
\hline GSE & $=$ & Ground Support Equipment \\
\hline GRASP & $=$ & Green Advanced Space Propulsion \\
\hline HMIS & $=$ & Hazardous Materials Identification System \\
\hline KSC & $=$ & Kennedy Space Center \\
\hline MMH & $=$ & Monomethyl Hydrazine \\
\hline MSDS & $=$ & Material Safety Data Sheet \\
\hline NASA & $=$ & National Aeronautics and Space Administration \\
\hline NFPA & $=$ & National Fire Protection Association \\
\hline NTO & $=$ & Nitrogen Tetroxide \\
\hline OSHA & $=$ & Occupational Safety and Health Administration \\
\hline PPE & $=$ & Personal Protective Equipment \\
\hline PRISMA & - & Prototype Research Instruments and Space Mission technology Advancement \\
\hline RCS & - & Reaction Control System \\
\hline REACH & - & Registration, Evaluation, Authorization and Restriction of Chemical substances \\
\hline
\end{tabular}




$\begin{array}{lll}\text { SCAPE } & - & \text { Self-Contained Atmospheric Protective Ensemble } \\ \text { TRL } & - & \text { Test Readiness Level } \\ \text { UDMH } & - & \text { Unsymmetrical Dimethyl Hydrazine } \\ \text { U. N. } & - & \text { United Nations } \\ \text { U. S. } & - & \text { United States } \\ & & \\ & & \\ \mathrm{I}_{\mathrm{sp}} & - & \text { Specific impulse, } \mathrm{s} \\ \rho & - & \text { Density, } \mathrm{kg} / \mathrm{m}^{3}\left(\mathrm{lbm} / \mathrm{ft}^{3}\right) \\ \mathrm{LD}_{50} & - & \text { Lethal Dose for } 50 \text { percent of population, } \mathrm{mg} / \mathrm{kg} \\ \mathrm{T}_{\mathrm{c}} & - & \text { Decomposition } / \mathrm{chamber} \text { temperature, } \mathrm{K}\left({ }^{\circ} \mathrm{R}\right) \\ \Delta \mathrm{V} & - & \text { Change in velocity, } \mathrm{m} / \mathrm{s}(\mathrm{ft} / \mathrm{s})\end{array}$

\section{Introduction}

In the last few years, interest has been gaining in less toxic replacements for hydrazine and its derivatives for inspace thruster systems. ${ }^{1-10}$ While bi-propellants offer some advantages in terms of handling and performance, the focus of this paper will be limited to monopropellant systems, because this is where much of the advancement in recent years has focused. In government and industry standards within the propulsion community there has not been a consistent definition of what constitutes "non-toxic" or "green", 11 and this paper will seek to provide some key figures of merit to help in the selection of propellant formulations. The paper will look at the history of hydrazine, and what considerations must be taken when selecting a suitable replacement propellant with the aim of reduced toxicity, safer handling characteristics, and improved performance compared to current the hydrazine infrastructure.

\section{A. Nomenclature}

While the terms "non-toxic" or "green" propellants are common phrases that are used for the desired propellant alternatives to hydrazine, there is no real solid definition as to what these mean according to the various standards in existence. These standards will be discussed further, but the desire is to replace hydrazine with a propellant that has significantly lower toxicity. Note that even the leading non-toxic propellant formulations being developed do not meet a wholly "non-toxic" definition by all the toxicity standards. Even commonplace chemicals like table salt $(\mathrm{NaCl})$ have an inherent, albeit high threshold, level of toxicity. ${ }^{12}$ The goal is to replace hydrazine, which is seen not only as toxic but treated as likely carcinogenic in humans, with a propellant that will have a corresponding greater level of safety as well as a reduction in handling complexity and cost, while maintaining or improving performance. Claiming a "non-toxic propellant" or "green propellant" may be a misnomer because these terms imply benign or environmentally friendly characteristics. "Reduced toxicity propellants" or "lower toxicity propellants" are other common terms which are more accurate descriptors. However, since "green" is so commonly and widely used in the literature, this paper will continue to use that term as the descriptor for reduced toxicity propellants.

\section{B. Historical Use of Hydrazine}

Hydrazine (i.e. anhydrous hydrazine, $\mathrm{N}_{2} \mathrm{H}_{4}$ ) and its derivatives (monomethylhydrazine [MMH], unsymmetrical dimethylhydrazine [UDMH], etc.) have traditionally been used as rocket propellants since the early 1960's. Hydrazine can either be paired with an oxidizer as a bi-propellant (as in the hydrazine - nitrogen tetroxide combination), or used alone with a catalyst as a monopropellant. Monopropellants are typically single component compounds which energetically decompose over a catalytic surface, as opposed to requiring some form of separate fuel/oxidizer combination and/or a spark ignition scheme. As early as 1973, the use of monopropellant hydrazine had become so common that thrusters using hydrazine as a propellant had been used almost exclusively compared to 
any other propellant. ${ }^{13}$ Monopropellant hydrazine was first used on the Able-4 lunar spacecraft in 1959, and in flight in 1966 as part of the Titan I launch vehicle. ${ }^{14,15}$

Hydrazine is an attractive propellant for several reasons. The development of the Shell 405 (later remanufactured by Aerojet as S-405) catalyst in the mid-late 1960's provided rocket designers with a convenient way to decompose hydrazine ${ }^{16,17}$ and has been recognized as being a significant contributor to the development of hydrazine monopropellant thrusters. ${ }^{13}$ Hydrazine as a monopropellant offers greater specific impulse than the coldgas thrusters developed prior to the mid-1960's and offers a simpler system than bi-propellant thrusters since it only requires one set of tankage. ${ }^{14,15}$ Additionally, hydrazine also has a relatively low decomposition/chamber temperature ( 800-900 K [1440-1620 $\left.{ }^{\circ} \mathrm{R}\right]$ ), meaning that low cost materials (such as stainless steels and aluminum alloys) may be employed for thruster chambers and components. ${ }^{14,18}$ Another advantage to hydrazine systems is a historical familiarity. Prior to its mass development as a monopropellant, a single energetically decomposing liquid had not existed with the efficiency and capability that hydrazine possesses. Because of the development of the Shell 405 catalyst/hydrazine thrusters, it rapidly became widely accepted through the rocket, missile, and energy generation communities. It has been a routinely selected propellant since the 1960's. Due to the massive acceptance, a variety of hardware (thrusters, tanks, valves, etc.) have been qualified as propulsion system components. ${ }^{14,15}$ This is particularly attractive to mission managers who must strive to buy down risk on spaceflight hardware so they have remained with the known propellant and heritage hardware. Incorporating a propulsion system and components which have not been extensively flight tested (Test Readiness Level (TRL) $<7-8$ ) is seen as high risk for most missions. Though some of these green propellants have been developed for decades, a propulsion system using these would require flying not only a new propellant but a novel catalyst and other new components adapted to these propellants, most of which is assessed at TRL $\sim 5$ or below at present. Additionally, the existing knowledge base also applies in the handling procedures, Price ${ }^{14}$ notes that while hydrazine is not to be casually handled, that handling is "relatively straightforward". There is already an extensive infrastructure in place for hydrazine fueling operations.

Since hydrazine has been in use for some time, its traits are well defined. Table 1 lists some of the properties of hydrazine. ${ }^{1,14,19}$ In order to gain the acceptance that hydrazine did, any alternative will have to meet or improve upon the properties and/or performance of hydrazine. While some of these parameters are pertinent to performance such as the density, specific impulse, and resulting density specific impulse, others are more directly related to the hazardous nature of hydrazine. For example, the vapor pressure of hydrazine is relatively low, meaning that it remains in liquid state in the event of a spill. This is attractive because it minimizes respiratory hazards in the event of spills. By contrast, the vapor pressure of ethanol, another common liquid propellant, is higher ( 0.82 psia) than for hydrazine ( $0.29 \mathrm{psia}$ ). Ensuring that material compatibilities, required thermal control, and vapor pressure of any hydrazine replacement are equal to or better than hydrazine could all help promote safety and make handling easier and more economical. 
Table 1: Properties of hydrazine.

\begin{tabular}{|c|c|}
\hline Parameter & Value \\
\hline Chemical Formula & $\mathrm{N}_{2} \mathrm{H}_{4}$ \\
\hline Molecular Weight & 32.05 \\
\hline Density @ $300 \mathrm{~K}, \mathrm{~kg} / \mathrm{m}^{3}$ & 1004 \\
\hline Vapor Pressure, kPa (psia)@ $300 \mathrm{~K}$ & $1.97(0.29)$ \\
\hline Specific Impulse, $\mathrm{s}$ & $220-235$ \\
\hline Density Specific Impulse, $\mathrm{kg}-\mathrm{s} / \mathrm{m}^{3}$ & $224 \times 10^{3}$ \\
\hline Compatible Materials & $\begin{array}{l}\text { 18-8 Stainless Steel, Most Aluminums, Most Titaniums, } \\
\text { Teflon, Kel-F, Polyethylene, Butyl Rubber }\end{array}$ \\
\hline Freezing Temperature, $\mathrm{K}(\mathrm{R})$ & $275(495)$ \\
\hline Boiling Temperature, K (R) & $387(697)$ \\
\hline
\end{tabular}

\section{Necessity for a Hydrazine Alternative}

Despite the long history and knowledge based gathered with hydrazine, there has been a strong push to discontinue its use as a monopropellant. One of the chief disadvantages of hydrazine is toxicity. Hydrazine is classified as an E. U. toxic and environmental hazard (marked as " $\mathrm{T}$ " and " $\mathrm{N}$ " on placards, respectively), and in the U. S. is labeled by the National Fire Prevention Association (NFPA) Standard 704 as level 3 in health, fire and reactivity. ${ }^{20}$ The NFPA levels will be discussed in more detail in a following section, but health ratings above level 3 mean that upon exposure it can cause both temporary and permanent debilitating effects with the potential of death. For hydrazine, this manifests in eye, throat, and nose irritation, blindness, headaches, nausea, pulmonary edema, seizures, and coma. It can severely damage the liver, kidneys, and central nervous system. It is corrosive and causes chemical burns with lasting severe dermatitis if exposed to the skin. ${ }^{21}$ Contrast this to ethanol, which is categorized by NFPA 704 as level 2 in health. ${ }^{22}$ Hydrazine is also recognized as a probable carcinogen that can cause cancer in humans upon exposure. One material safety data sheet (MSDS) for hydrazine notes that it may be fatal if absorbed through the skin, ${ }^{20}$ while another notes that in the event of a spill, the area is to be evacuated immediately. ${ }^{23}$ This second MSDS has a more severe NFPA 704 rating for hydrazine, labeling it as level 4 in health; however the level 3 ratings for health seem to be more consistent across the MSDS search. In either case, both MSDS contain strong language to avoid exposure. Europe is also strongly seeking to discontinue hydrazine usage through REACH and GRASP efforts. ${ }^{7}$

While hydrazine and other hypergolic propellants have many favorable storage and performance properties, recognized over 30 years of use, they are becoming much more problematic from a cost and handling perspective. As early as 1995, studies have been conducted to look at alternatives to these propellants. ${ }^{2}$ Because of the now required self-contained hazardous material suits (e.g. SCAPE suits), extra procedural requirements, increased costs for hardware replacement due to corrosion, and other hazardous material handling equipment, ground costs for hydrazine operations are increasing. ${ }^{24}$ Compared to several other common propellants, hydrazine has the most stringent quantity distance requirements and accidental release measures. ${ }^{25}$ Additionally, the cost for bulk hydrazine has also increased significantly. Since 2002, costs for bulk hydrazine (anhydrous) have increased by 200 percent. $^{26}$ Some propellants under current investigation as hydrazine replacements claim a greater than $2 / 3$ cost savings in ground operation costs versus a similar sized hydrazine system. ${ }^{27,28}$

\section{Scope and Figures of Merit}

There are numerous characteristics which may be viewed when comparing a propellant to the current state of the art with hydrazine. For this body of work, three major factors were considered: toxicity, handling and transportation, and performance. Toxicity is a major concern, because it both increases the required personnel safety 
measures, but also concerning potential environmental impacts (hazards with spills or mishaps). Handling and transportation are concerns because the required costs and delays of ground operations can significantly contribute to monetary costs and schedule. Performance is a major concern of mission planners because it directly relates to the size and mass (and thus cost) of a given spacecraft. The higher performing a propellant, the smaller tanks potentially required, and therefore the greater amount of mass savings for instrumentation. When speaking of figures of merit, these are the major areas on which to focus when comparing/selecting propellant options.

\section{A. Toxicity}

The term "non-toxic" has been used in touting the goals for replacing hydrazine yet this term is rarely defined in detail. Various definitions of toxicity all include references to substances of a chemical nature that can inflict debilitation, damage, or death upon entering an organism. More detailed definitions include a caveat along the lines of "in certain quantities or concentrations".

In quantifying a substance as toxic, the concentration issue becomes a key factor. There are a multitude of standards in existence generated by various agencies that address acute toxicity. These ratings may take into account considerations for their specific industries; for example the National Fire Protection Association (NFPA) fire diamond sets health hazard levels, which account for toxicity, based on the assumption that a chemical will be exposed to fire. Their standard is used to quickly recognize the level of threat present and determine the appropriate equipment and exposure duration that can be withstood. These levels largely serve as a representation of concentration limits that can be endured. To properly deal with these chemicals the respective material safety data sheets (MSDS) must be referenced to determine appropriate handling methods. ${ }^{29}$ A chemical may be categorized (as indicated on the MSDS) by a combination of toxicity standards, including various United States and European standards.

In terms of exposure duration, not only do these various standards have concentration thresholds (the amount of substance) but there is also a time-dependency (how long one can be exposed to the given concentration) associated with them. These standards have an assigned exposure period and rules for scaling concentrations proportionately with the exposure period. Table 2 shows a cross section of various standards for oral toxicity; the quantity that could be ingested orally before a fatal level is likely reached. The $\mathrm{LD}_{50}$ (Lethal Dose for 50 percent of the population) parameter that is given for these values is a commonly used parameter for all of these standards representative of the dose of the substance (typically in $\mathrm{mg}$ ) that would be required per unit mass of a subject (typically in $\mathrm{kg}$ ) that would result in the death of 50 percent of the administered sample population. These populations are typically representative animal species such as mice, though testing has been administered to various other mammal and non-mammal species as well. There are other non-animal testing ways to parameterize the $\mathrm{LD}_{50}$ that have been developed in more recent years, though this has not been widely implemented. The acute oral toxicity values shown in Table 2 are adjusted for a four hour equivalent exposure.

The table also shows that not all of these standards have similar cutoffs or even a similar number of categories. The names of the categories also vary, with "toxic" labels being used across differing spans, and some systems using "categories" or "levels". The highlighted category is the Globally Harmonized System (GHS) which is a project by the United Nations (U. N.) that seeks to create a uniform standard for all applications and countries to aid international commerce and ensure safety. This standard avoids labels in favor of a strictly categorized system, as seen in Table 3. This table shows not only the acute oral dosage limits but also the various other means of acute toxicity exposure; dermal, gases, vapors, and dusts \& mists. All of the aforementioned various standards typically include breakdowns for each of these categories as well, further adding to the complexity of these systems. 
Generally a given category or level within a classification system will have a degree of effect associated with that level of exposure. For the highest toxicity levels, death is often a common effect. Some example statements from the Hazardous Materials Identification System (HMIS) and NFPA standards are stated in Table 4. To ground this discussion on toxicity, hydrazine falls in the $3^{\text {rd }}$ level for this health and toxic aspect, according to the NFPA standards, and would thus be considered "highly toxic" by OSHA standards. ${ }^{20}$

Table 2: Comparison of acute toxicity standards ${ }^{31}$

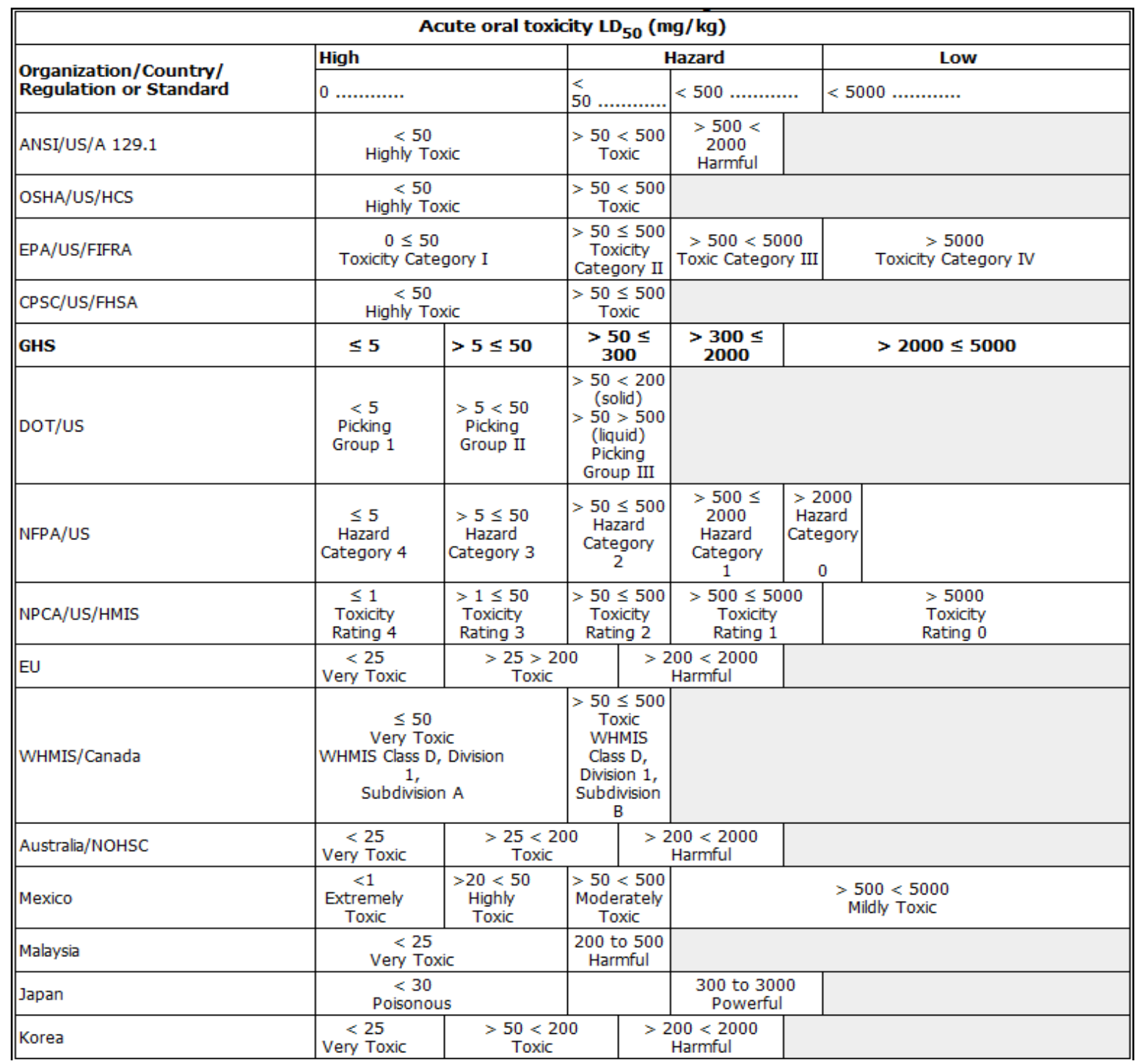

Further complications in the adequate classification of new propellants are seen when the propellants are blends of multiple constituents. As the propellants are developed, a toxicity rating for the blend may not have been determined, but ratings for each constituent component may exist. However, the blended propellant may be less harmful overall than the individual components. For example, a propellant may be made less harmful due to dilution or the inability of a more harmful component to come out of solution. Initial safety measures may have to use the "worst case" ratings of the constituent components until the overall product is evaluated. A thorough 
evaluation of these should be carried out with documented results. The benefit of reduced cost due to easier handling will only be realized if the propellant blends are rated safer.

Table 3: Acute toxicity categories for all means of exposure per U. N. Globally Harmonized System ${ }^{31}$

\begin{tabular}{|c|c|c|c|c|c|}
\hline $\begin{array}{l}\text { Acute } \\
\text { toxicity }\end{array}$ & Cat. 1 & Cat. 2 & Cat. 3 & Cat. 4 & Category 5 \\
\hline $\begin{array}{l}\text { Oral } \\
(\mathrm{mg} / \mathrm{kg})\end{array}$ & $\leq 5$ & $\begin{array}{l}>5 \\
\leq 50 \\
\end{array}$ & $\begin{array}{l}>50 \\
\leq 300 \\
\end{array}$ & $\begin{array}{l}>300 \\
\leq 2000 \\
\end{array}$ & \multirow{5}{*}{$\begin{array}{l}\text { Criteria: } \\
\text { - Anticipated oral LD50 between } 2000 \text { and } 5000 \mathrm{mg} / \mathrm{kg} \text {; } \\
\text { - Indication of significant effect in humans; }{ }^{*} \\
\text { - Any mortality at class } 4 ;^{*} \\
\text { - Significant clinical signs at class } 4 ;^{*} \\
\text { - Indications from other studies.* } \\
\text { *If assignment to more hazardous class is not warranted. }\end{array}$} \\
\hline $\begin{array}{l}\text { Dermal } \\
(\mathrm{mg} / \mathrm{kg})\end{array}$ & $\leq 50$ & $\begin{array}{l}>50 \\
\leq 200 \\
\end{array}$ & $\begin{array}{l}>200 \\
\leq 1000\end{array}$ & $\begin{array}{l}>1000 \\
\leq 2000\end{array}$ & \\
\hline $\begin{array}{l}\text { Gases } \\
(\mathrm{ppm})\end{array}$ & $\leq 100$ & $\begin{array}{l}>100 \\
\leq 500 \\
\end{array}$ & $\begin{array}{l}>500 \\
\leq 2500 \\
\end{array}$ & $\begin{array}{l}>2500 \\
\leq 5000 \\
\end{array}$ & \\
\hline $\begin{array}{l}\text { Vapors } \\
(\mathrm{mg} / \mathrm{l})\end{array}$ & $\leq 0.5$ & $\begin{array}{l}>0.5 \\
\leq 2.0 \\
\end{array}$ & $\begin{array}{l}>2.0 \\
\leq 10\end{array}$ & $\begin{array}{l}>10 \\
\leq 20\end{array}$ & \\
\hline $\begin{array}{l}\text { Dust \& mists } \\
(\mathrm{mg} / \mathrm{l})\end{array}$ & $\leq 0.05$ & $\begin{array}{l}>0.05 \\
\leq 0.5\end{array}$ & $\begin{array}{l}>0.5 \\
\leq 1.0\end{array}$ & $\begin{array}{l}>1.0 \\
\leq 5\end{array}$ & \\
\hline
\end{tabular}

Finally, in addition to acute toxicity, there are additional exposure hazard concerns. Among these are carcinogenicity, mutagenicity, reproductive toxicity, along with specific organ sensitivity and other dangers. ${ }^{30}$ Hydrazine, for example, has been proven as a carcinogenic substance. ${ }^{20}$ In order to reduce risk, ensure safety, and enable potential cost savings, these hazards should be eliminated in future propellants.

\section{Table 4: Comparison of toxicity level thresholds}

\begin{tabular}{|c|l|l|l|}
\hline Level & $\begin{array}{c}\text { (Hazardous Materials Identification } \\
\text { System (HMIS) }\end{array}$ & $\begin{array}{l}\text { National Fire Protection Association } \\
\text { (NFPA) }\end{array}$ & $\begin{array}{c}\text { Occupational Safety and Health } \\
\text { Administration (OSHA) }\end{array}$ \\
\hline $\mathbf{4}$ & $\begin{array}{l}\text { Life-threatening, major or permanent } \\
\text { damage may result from single or } \\
\text { repeated overexposures }\end{array}$ & $\begin{array}{l}\text { Very short exposure could cause death } \\
\text { or serious residual injury even though } \\
\text { prompt medical attention was given }\end{array}$ & Highly Toxic \\
\hline $\mathbf{3}$ & $\begin{array}{l}\text { Major injury likely unless prompt } \\
\text { action is taken and medical treatment is } \\
\text { given }\end{array}$ & $\begin{array}{l}\text { Short exposure could cause serious } \\
\text { temporary or residual injury even } \\
\text { though prompt medical attention was } \\
\text { given }\end{array}$ & Highly Toxic \\
\hline $\mathbf{2}$ & Temporary or minor injury may occur & $\begin{array}{l}\text { Intense or continued exposure could } \\
\text { cause temporary incapacitation or } \\
\text { possible residual injury unless prompt } \\
\text { medical attention is given }\end{array}$ & Toxic \\
\hline $\mathbf{0}$ & Irritation or minor reversible injury & $\begin{array}{l}\text { Exposure could cause irritation but only } \\
\text { minor residual injury even if no } \\
\text { treatment is given }\end{array}$ & n/a \\
\hline
\end{tabular}

\section{B. Handling and Transportation}

Due to the hazards of hydrazine, one of the most severe levels of personal protective equipment is required. The material safety data sheet (MSDS) for this propellant states that a full suit with face shield and respirator is required for the propellant and in the case of a large spill a full self-contained breathing apparatus is required. ${ }^{20}$ As common practice in the industry, Self-Contained Atmospheric Protective Ensemble (SCAPE) suits are worn to protect against the propellant and its toxic effects. ${ }^{24}$ Potential green propellants and their lower toxicity levels could have comparatively less requisite protective equipment. ${ }^{28}$ Some of the propellants under current evaluation require less stringent respiratory protection. Though they generally still require gloves and coveralls with goggles or face shields, they do not typically require a fully sealed suit. 
Due to these less stringent handling requirements, spacecraft processing would not need to be suspended for fueling operations. Not only would there be a reduction in the monetary costs of operations, there would be a shortened schedule with each one of these tasks and there would be a corresponding lower time demand on personnel. With hydrazine, fueling operations require the evacuation of all personnel other than those directly involved in the fueling procedure. ${ }^{28}$ This means that time must be set aside specifically for these operations and all other work must cease. The ease of handling of green propellants would not only reduce delays caused by these operations but potentially allow other work to continue concurrently. A caveat to this is that the new propellants should be qualified to be to not introduce additional propellant loading or handling restrictions as compared to hydrazine. It should tolerate a similar or less restrictive environment with regards to static charge, mechanical shock and friction, ambient temperature regime, among other assembly, loading, and launch site concerns.

One of the main advantages of replacing hydrazine, aside from the greater degree of safety to personnel, is in the possible reduced cost associated with ease of transport. Other studies have examined the resulting costs savings that can be incurred by the usage of reduced toxicity propellants as compared to their toxic predecessors. ${ }^{4,7}$ These studies discuss how savings in time and direct costs can be achieved through the whole process of launching a spacecraft. With a less hazardous propellant, there is the potential for reducing costs by requiring a less complex propellant flow system, since a more toxic propellant requires more failure prevention devices and safety measures. Similarly, there would be a corresponding reduction in the required ground support equipment (GSE) and support personnel devoted to propellant handling operations.

U. N. and Department of Transportation (DOT) packing and shipping policies are additional concerns that need to be minded. While some of the green propellants may fall in different classifications entirely from hydrazine (DOT hazard classification 8 , corrosive, packing group I), acceptable shipping standards for these propellants must be achieved since this may still be considered a hazardous operation. ${ }^{32}$ Acceptable shipping classifications are another potential point of cost savings that new propellants may achieve. There may not be an even basis to compare between shipping classifications, but preference should be given to propellants that can be transported by the most means and with less induced cost. Preference to less restrictive shipping reduces the need for special packaging and transportation modes, and thus can the propellant can be shipped more conventionally at lower costs. Each of the various hazard classes or divisions have three subset packing groups with 'I' being the most stringent and 'III' being least so, with the more stringent group requiring more specialized handling and greater associated costs. An improvement over this packing group is desired. Likewise, due to the shipping classifications that hydrazine falls under, it is forbidden to be transported by passenger rail or passenger air. In the case of cargo air, it is restricted to quantities of $2.5 \mathrm{~L}$. Given that spacecraft typically use several liters of propellant, this restriction severely limits transportation modes for hydrazine. Achieving a different classification can potentially enable transport on passenger modes or enable the air transport of larger quantities. This would allow for greater flexibility and potentially lower costs in the ground phase of a mission.

Additionally, due to the less stringent handling and safety requirements with green propellants, potentially lower bulk costs of the propellants may be achieved, since some of the high costs in hydrazine are due to the increased safety measures and protocols associated with large quantities. ${ }^{7}$

\section{Performance and Material Compatibility}

While toxicity and handling are the primary focus of interest in a hydrazine replacement, the performance of a propellant cannot be overlooked. There are a number of methods to determine performance for a monopropellant. Three parameters are usually recognized as critical and they are specific impulse $\left(\mathrm{I}_{\mathrm{sp}}\right)$, density specific impulse $\left(\rho I_{s p}\right)$, and decomposition or chamber temperature $\left(T_{c}\right)$. Specific impulse and density specific impulse are useful for determining the size and mass of the required tankage and available $\Delta \mathrm{V}$ for a given mission. Decomposition temperature determines the materials required (either catalyst or chamber) for thruster survivability. Goals by various parties have been stated that any hydrazine replacement has, as a minimum, the same or better performance 
characteristics as compared to hydrazine. ${ }^{33}$ The closer a propellant can perform to current hydrazine propulsion systems; the more readily it can be implemented as a drop-in replacement, saving development costs. The noted typical performance parameters for hydrazine are provided in Table 1. Other considerations of performance include response time (how long it takes for the propellant to combust once injected into the chamber) and any system considerations such as pre-heat requirements.

While the green propellants should be at minimum equal to hydrazine in all aspects, many of the current reported propellants under development show significantly increased performance over hydrazine despite having different heater or pulse characteristics. Thus while not equal in all aspects, improvements in specific impulse performance makes them very attractive as a hydrazine substitute. For a given impulse requirement, improved density specific impulse would require less volume of propellant. Thus, a potentially smaller propulsion system may be needed as compared to hydrazine. For a specific mission, this may enable larger payloads, longer mission life, or improved capability for the same amount of mass as a traditional hydrazine system.

With increased performance, green monopropellants may exceed the traditionally achieved performance range of hydrazine based monopropellants and even approach the ranges of hypergolic bi-propellants or even traditionally ignited space storable bi-propellants as detailed in Figure 1. These green propellants can be seen as not only replacing and expanding the performance of traditional monopropellants but also closing a performance gap. Eliminating the need for secondary storage and flow systems required of bipropellants could allow for payload mass and capability enhancements.

Requirements for catalyst bed heating should also be considered. Some of the ionic liquid monopropellants require pre-heated catalyst beds for proper and efficient combustion. Pre-heat requirements determine the amount of power draw required on satellite systems, which are power limited. The lower the catalyst pre-heat temperature the more quickly a system can be used on short notice which is attractive for applications such as Divert and Attitude Control Systems (DACS) or Reaction Control Systems (RCS). The state of the art in hydrazine propulsion, the Shell/S-405 catalyst, does not require any pre-heat and is capable of many spontaneous starts, even at temperatures as low as $273 \mathrm{~K}\left(492^{\circ} \mathrm{R}\right) .{ }^{14,16}$ Though catalyst temperature is one consideration, this is a potential trade with temperature regulation of the propellant tanks and flow systems. These are factors important in system architecture, but each propellant will have its own beneficial and hindering attributes.

As the current state of the art and most major developments in monopropellants are intrinsically dependent on a catalyst surface to function, the catalyst itself must be considered. While catalysts by their nature are not consumed, the potentially harsh chemical and thermal environments that are characteristic of monopropellant decomposition and combustion can cause the destruction of the catalyst through a variety of mechanisms. ${ }^{34}$ Since these new propellant systems will need to meet or exceed the performance of comparable hydrazine propulsion systems, a similar operational lifespan must be met and a similar range of duty cycles to the current performance of hydrazine on S-405 must be achieved. ${ }^{28}$ Likewise, there cannot be a significant change in total system mass due to a heavier flow system and/or catalyst that is not compensated by the increased propellant performance. The desire is for comparable vehicle system performance, though these new propellant and catalyst combinations may result in increased capability as well. Along with lifespan, other combustion related concerns like roughness and ignition delay should meet or exceed the current performance of hydrazine thrusters. These parameters are all typically dependent to some degree on the thrust class of the thruster and should be equated accordingly. 


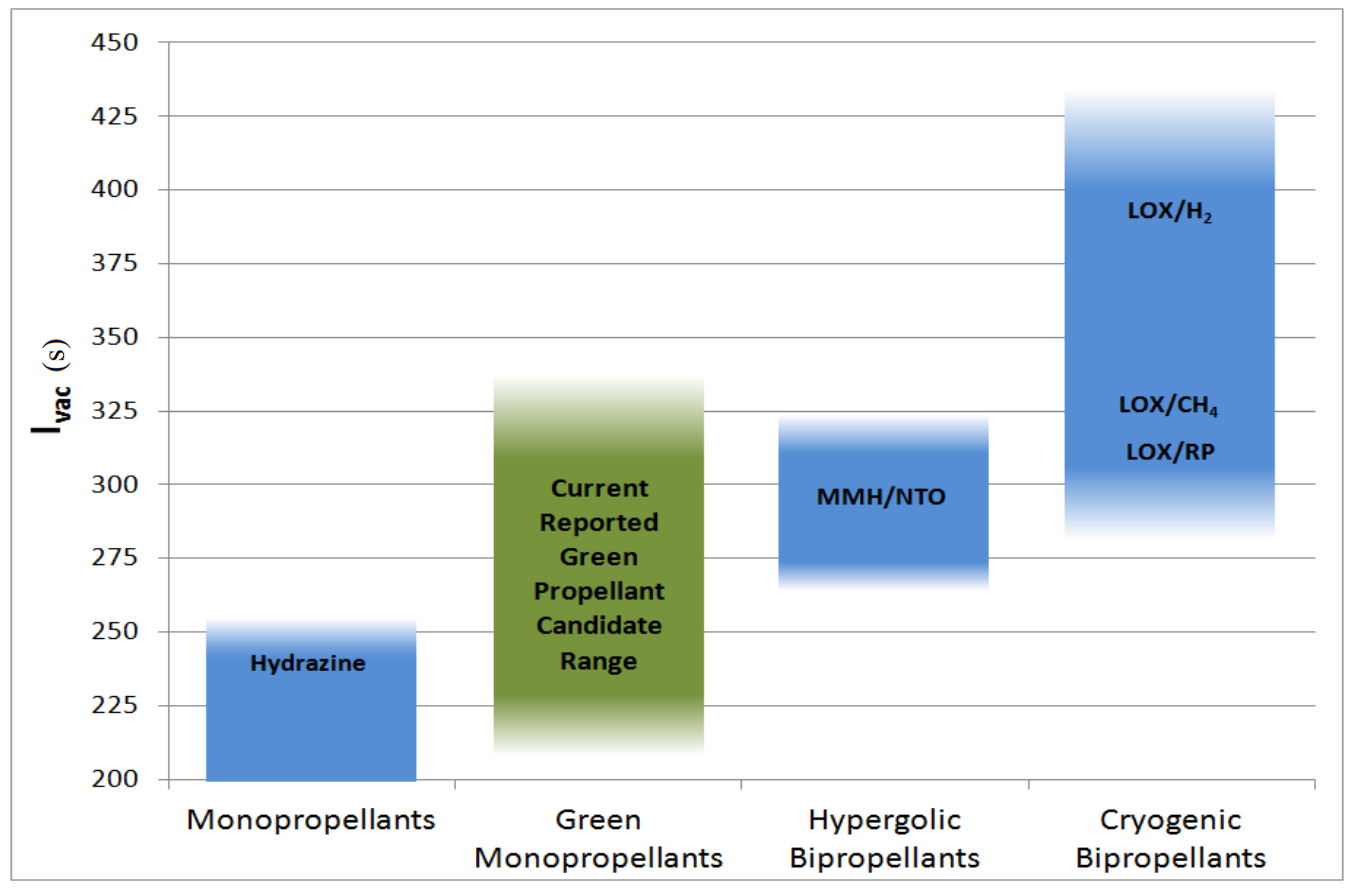

Figure 1: Vacuum specific impulse performance ranges by propellant type - based upon 300 psia chamber pressure and nozzle expansion ratio of 40:1

There have been various efforts into igniting monopropellants without a catalyst. Any alternate form of ignition must likewise meet or exceed the lifespan, response, and duty cycle capabilities of current hydrazine systems.

Since many of the chemicals used as traditional monopropellants have been used in hypergolic bipropellant systems as well, many of the hypergolic bipropellants are also very toxic. Research into green hypergolic propellants should also be an important consideration as well to further ensure safety, lessen cost, and potentially expand capability. Cost savings could be further accrued should the same propellant used as a monopropellant be used as a component in bi-propellant systems, since fewer handling systems would be required and handling operations could potentially be combined.

\section{Discussion and Recommendations}

As can be seen from the extensive review above, comparing and unifying the various standards, codes and performance expectations is complex and difficult. The goal of this paper is not to dictate industry standards or policies. However, an extensive review of the literature provides some view of the overall desires and suggestions for improvement. Thus, this paper seeks to make recommendations that cover most concerns.

From a toxicity standpoint, efforts are under way to establish an international, universal standard, but those efforts are not complete and current standards are not always in agreement. Compounding the classification of new propellants comes when the propellants are blends of multiple constituents. As the propellants are developed, a toxicity rating for the blend may not have been determined, but ratings for each constituent component may exist. However, the blended propellant may be less harmful overall than the individual components due, for example, to dilution effects or the inability of the component to come out of solution. Initial safety measures may have to use the "worst case" ratings of the constituent components until the overall product is evaluated. A thorough evaluation of these should be carried out with documented results as the benefit of reduced cost due to easier handling will only be realized if the propellant blends are rated safer. Achieving a NFPA and HMIS health category level lower than 
that of hydrazine is the desired goal. Any secondary health concerns (carcinogenic, mutagenic, etc.) should also be eliminated.

With respect to handling and transportation, recognizing that any propellant is likely to be categorized as a hazardous material, improvements to the available means of handling and transportation is desired. For instance, a propellant that can be shipped in meaningful quantities by commercial air would be desired over one which is restricted on commercial air, since this would provide managers the greatest flexibility in transporting propellant for schedule sensitive operations. Additionally, a reduction in required PPE (such as eliminating SCAPE suit requirements) is highly desirable.

As a minimum, any propellant should have the same overall performance $\left(I_{\mathrm{sp}}\right.$ and $\left.\rho \mathrm{I}_{\mathrm{sp}}\right)$ of hydrazine. Additionally, increasing chamber/catalyst lifespan and associated combustion properties like minimizing combustion delay and roughness are important goals, since this will increase the responsiveness and longevity for thruster replacements. The more potential for a system to be a drop in replacement for hydrazine systems, the more likely it will be adopted for future missions.

Table 5 sums up some of the pertinent goals concerning hydrazine replacements. Achieving these goals will not only yield a safer propellant but also enable efficiencies in cost and time. Note that these are goals, and it is recognized that a propellant may not meet all goals in the table. However, preference should be given to the propellants which meet the greatest set of goals. As a general rule of thumb, any propellant which would be used to replace hydrazine should meet two major criterion: 1.) It must have a performance (specific impulse or density specific impulse) as high or higher than hydrazine, and 2.) The ground handling considerations must be less hazardous (from a toxicity/safety viewpoint) and require less ground support equipment (from a personnel safety/handling viewpoint) than hydrazine.

Table 5: Propellant Replacement Goals

\begin{tabular}{|c|c|}
\hline Metric & Goal \\
\hline Acute Toxicity/Health & $\begin{array}{ll}- & \text { NFPA, HMIS }<3 \\
- & \text { OSHA }<\text { 'Highly Toxic' } \\
- & \text { GHS }>2\end{array}$ \\
\hline Exposure Hazards & - Non-carcinogenic, non-mutagenic \\
\hline Personal Protective Equipment (PPE) & - Eliminate need for SCAPE suits \\
\hline Transportation & $\begin{array}{l}\text { - } \\
\text { - } \\
\text { BOlk packing group II or III } \\
\text { shippable by commercial rail/air }\end{array}$ \\
\hline Performance & $\begin{array}{l}\text { - } \mathrm{I}_{\mathrm{sp}}>220-230 \mathrm{~s} \\
\text { - Reduce need for exotic materials } \\
\text { - } \quad \text { Combustion delay and roughness comparable to hydrazine monopropellant systems for } \\
\text { given thrust classes } \\
\text { - Lifespan comparable to hydrazine/S-405 monopropellant systems. }\end{array}$ \\
\hline
\end{tabular}




\section{References}

${ }^{1}$ Hurlbert, E., Applewhite, J., Nguyen, T., Reed, B., Baojiong, Z. and Yue, W., "Nontoxic Orbital Maneuvering and Reaction Control Systems for Reusable Spacecraft," Journal of Propulsion and Power, Vol. 14, No. 5, September-October 1998, pp. 676687.

${ }^{2}$ Cort, R., Hurlbert, E., Riccio, J. R. and Sanders, J., "Non-Toxic On-Orbit Propulsion for Advanced Space Vehicle Applications," AIAA 1995-2974, 31st AIAA/ASME/SAE/ASEE Joint Propulsion Conference and Exhibit, San Diego, CA, July 10-12, 1995.

${ }^{3}$ Bombelli, V., Marée, T. and Caramelli, F., "Non-Toxic Liquid Propellant Selection Method - A Requirement Oriented Approach," AIAA 2005-4453, 41st AIAA/ASME/SAE/ASEE Joint Propulsion Conference and Exhibit, Tuscon, AZ, July 10-13, 2005.

${ }^{4}$ Bombelli, V., Simon, D., Marée, T. and Moerel, J.-L., "Economic Benefits of the Use of Non-Toxic Mono-Propellants for Spacecraft Applications," AIAA 2003-4783, 39th AIAA/ASME/SAE/ASEE Joint Propulsion Conference and Exhibit, Huntsville, AL, July 20-23, 2003.

5 Austin, B. L., Heister, S. D. and Anderson, W. E., "Characterization of Pintle Engine Performance for Nontoxic Hypergolic Bipropellants," Journal of Propulsion and Power, Vol. 21, No. 4, July-August 2005, pp. 627-635.

${ }^{6}$ Valentian, D., Cucco, N., Muszynski, M., Souchier, A. and Maisonneuve, Y., "Green Propellants Perpectives for Future Missions," AIAA 2008-5028, 44th AIAA/ASME/SAE/ASEE Joint Propulsion Conference and Exhibit, Hartford, CT, July 21-23, 2008.

7 Scharlemann, C., "Green Advanced Space Propulsion - A Project Status," AIAA 2011-5630, 47th AIAA/ASME/SAE/ASEE Joint Propulsion Conference and Exhibit, San Diego, CA, July 31-August 3, 2011.

${ }^{8}$ Grayson, G. D., "Propellant Trade Study for a Crew Space Vehicle," AIAA 2005-4313, 41st AIAA/ASME/SAE/ASEE Joint Propulsion Conference and Exhibit, Tucson, AZ, July 10-13, 2005.

9 Smith, T. D., Klem, M. D. and Fisher, K., "Propulsion Risk Reduction Activities for Non-Toxic Cryogenic Propulsion," AIAA 2010-8680, AIAA Space 2010 Conference and Exhibit, Anaheim, CA, August 30 - September 2, 2010.

10 Accettura, A. G., "Green Propellants", Advanced Propulsion Systems and Technologies, Today to 2020, Chap. 6, C. Bruno and A. G. Accettura, Eds., Progress in Astronautics and Aeronautics Series, Series Vol. 223, American Institute of Aeronautics and Astronautics, Reston, VA, 2008, pp. 155-162.

11 Palyonov, B. A., Bessonov, A. I., Pastuhov, A. I., Shulkova, S. S. and Kalmykov, G. P., "Green Propellants in Russia", Advanced Propulsion Systems and Technologies, Today to 2020, Chap. 7, C. Bruno and A. G. Accettura, Eds., Progress in Astronautics and Aeronautics Series, Series Vol. 223, American Institute of Aeronautics and Astronautics, Reston, VA, 2008, pp. 163-171.

12 Fisher Scientific, "Material Safety Data Sheet (MSDS): Sodium Chloride," http://sscimage.fishersci.com/msds/21105.htm, Accessed: Nov. 2012.

13 Russi, M. J., "A Survey of Monopropellant Hydrazine Thruster Technology," AIAA 73-1263, AIAA/SAE 9th Propulsion Conference, Las Vegas, NV, November 5-7, 1973.

${ }^{14}$ Price, T. W. and Evans, D. D., "The Status of Monopropellant Hydrazine Technology," JPL TR 32-1227, National Aeronautics and Space Administration, Pasadena, CA, 1968.

15 Morgan, O. M. and Meinhardt, D. S., "Monopropellant Selection Criteria - Hydrazine and Other Options," AIAA 99-2595, 35th AIAA/ASME/SAE/ASEE Joint Propulsion Conference and Exhibit, Los Angeles, CA, June 20-23, 1999.

${ }^{16}$ Wucherer, E. J., Cook, T., Stiefel, M., Humphries, R. and Parker, J., "Hydrazine Catalyst Production - Sustaining S-405 Technology," AIAA 2003-5079, 39th AIAA/ASME/SAE/ASEE Joint Propulsion Conference and Exhibit, Huntsville, AL, July 20$23,2003$. 
${ }^{17}$ Schmitz, B. W., Smith, W. W., Williams, D. A. and Maybee, D., "Design and Scaling Criteria for Monopropellant Hydrazine Rocket Engines and Gas Generators Employing Shell 405 Catalyst," AIAA 66-594, AIAA Second Propulsion Joint Specialist Conference, Colorado Springs, CO, June 13-17, 1966.

18 Makled, A. E. and Belal, H., "Modeling of Hydrazine Decomposition for Monopropellant Thrusters," ASAT-13-PP-22, 13th International Conference on Aerospace Sciences and Aviation Technology, Cairo, Egypt, May 26-28, 2009.

${ }^{19}$ Giordano, D., "Survey of the Thermodynamic Properties of Hydrazine," Journal of Chemical and Engineering Data, Vol. 46, No. 3, March 31, 2001, pp. 486-505.

${ }^{20}$ Fisher Scientific, "Material Safety Data Sheet (MSDS): Hydrazine," http://fscimage.fishersci.com/msds/11040.htm, Accessed: Nov. 2012.

${ }^{21}$ Environmental Protection Agency, "Hydrazine," http://www.epa.gov/ttnatw01/hlthef/hydrazin.html, Nov. 2012.

22 Fisher Scientific, "Material Safety Data Sheet (MSDS): Ethyl Alcohol 200 Proof,"

http://fscimage.fishersci.com/msds/89308.htm, Accessed: Nov. 2012.

${ }^{23}$ InChem, "Material Safety Data Sheet (MSDS): Hydrazine," www.inchem.org/documents/icsc/icsc/eics0281.htm, Nov. 2012.

${ }^{24}$ MacLean, M. B. and Rodriguez, H., "A low-risk, reliable, operationally efficient auxillary propulsion system for the Reusable Launch Vehicle," AIAA 96-3228, AIAA/ASME/SAE/ASEE Joint Propulsion Conference and Exhibit, Lake Buena Vista, FL, July $1-3,1996$.

25 Wernimont, E. J., "System Trade Parameter Comparison of Monopropellants: Hydrogen Peroxide vs Hydrazine and Others," AIAA 2006-5236, 42nd AIAA/ASME/SAE/ASEE Joint Propulsion Conference and Exhibit, Sacramento, CA, July 9-12, 2006.

${ }^{26}$ Defense Logistics Agency: Energy, "Aerospace Energy Standard Prices,"

http://www.energy.dla.mil/customer/standard prices/Pages/AerospaceStandardPrices.aspx, Nov. 2012.

${ }^{27}$ Persson, M., Anflo, K., Dinardi, A. and Bahu, J.-M., "A Family of Thrusters for ADN-Based Monopropellant LMP-103S," AIAA 2012-3815, 48th AIAA/ASME/SAE/ASEE Joint Propulsion Conference \& Exhibit Atlanta, GA, July 30-August 1, 2012.

28 Anflo, K. and Crowe, B., "In-Space Demonstration of an ADN-Based Propulsion System," AIAA 2011-5832, 47th AIAA/ASME/SAE/ASEE Joint Propulsion Conference and Exhibit, San Diego, CA, July 31-August 3, 2011.

${ }^{29}$ National Fire Protection Association, "National Fire Protection Association - FAQ," http://www.nfpa.org/faq.asp?categoryID=928\&cookie\%5Ftest=1, 9/20/2012.

${ }^{30}$ Occupational Safety and Health Administration, "Appendix A TO $§ 1910.1200$ - Health Hazard Criteria (Mandatory)," http://www.osha.gov/pls/oshaweb/owadisp.show document?p table=STANDARDS\&p id=10100, 9/20/2012.

31 Occupational Safety and Health Administration, "A Guide to The Globally Harmonized System of Classification and Labelling of Chemicals (GHS)," http://www.osha.gov/dsg/hazcom/ghs.html, 9/20/2012.

32 Neff, K., King, P., Anflo, K. and Mollerberg, R., "High Performance Green Propellant for Satellite Applications," AIAA 2009-4878, 45th AIAA/ASME/SAE/ASEE Joint Propulsion Conference \& Exhibit, Denver, CO, August 2-5, 2009.

33 Zube, D. M., Wucherer, E. J. and Reed, B., "Evaluation of HAN-Based Propellant Blends," AIAA 2003-4643, 39th AIAA/ASME/SAE/ASEE Joint Propulsion Conference and Exhibit, Huntsville, AL, July 20-23, 2003.

${ }^{34}$ Hearn, H. C., "Effect of duty cycle on catalytic thruster degradation," Journal of Spacecraft and Rockets, Vol. 18, No. 3, MayJune 1981, pp. 216-221. 